\title{
The Extending Network of FOXO Transcriptional Target Genes
}

\author{
Kristan E. van der Vos ${ }^{1}$ and Paul J. Coffer ${ }^{1,2}$
}

\begin{abstract}
The evolutionarily conserved Forkhead box O (FOXO) family of transcription factors regulates multiple transcriptional targets involved in various cellular processes, including proliferation, stress resistance, apoptosis, and metabolism. Target gene regulation appears to be controlled in a cell-type-specific manner due to association of FOXO isoforms with specific cofactors. Many of the cellular processes modulated by FOXO are themselves deregulated in tumorigenesis, and deletion of Foxo genes has demonstrated that these transcription factors function as tumor suppressors. Our understanding of the regulation of FOXO activity, and defining specific transcriptional targets, may provide clues to the molecular mechanisms controlling cell fate decisions. In this review we describe the functional consequences of FOXO activation based on our current knowledge of transcriptional targets. Antioxid. Redox Signal. 14, 579-592.
\end{abstract}

\section{Introduction}

$\mathbf{T}$ HE FORKHEAD TRANSCRIPTION FACTOR family is characterized by a winged-helix DNA binding motif, the forkhead domain [reviewed in (68)], and the subfamily of Forkhead box $\mathrm{O}$ (FOXO) has been defined on the basis of sequence homology within this domain. A single FOXO transcription factor has been identified in both the nematode worm Caenorhabditis elegans, termed DAF-16 (abnormal dauer formation protein 16), and in the fruit fly, Drosophila melanogaster; named dFOXO. In mammalian cells, four FOXO orthologs have now been identified and characterized: FOXO1, FOXO3, FOXO4, and FOXO6. FOXO1, FOXO3, and FOXO4 are relatively ubiquitously expressed, with FOXO1 expression being the highest in adipose tissue, FOXO3 is being predominantly expressed in heart, brain, kidneys, and ovaries, and $\mathrm{FOXO} 4$ showing highest expression in muscle and heart tissue $(4,9,31)$. FOXO6 appears to be uniquely expressed in brain, but whether it is also expressed in additional tissues remains unclear (44).

Alignment of amino acid sequence of FOXO proteins with other members of the larger group of forkhead transcription factors reveals that the DNA binding domain (DBD) is highly conserved (Fig. 1). Due to this, all FOXOs share a similar DNA binding specificity, with the core binding motif being defined as TTGTTTAC (32). The DNA binding domain of FOXOs consists of three $\alpha$-helices (H1, H2, and H3), three $\beta$-strands (S1, S2, and S3), and two wing-like loops (W1 and
W2). Crystallization of the FOXO4 DBD bound to DNA has revealed that FOXOs bind DNA through multiple interactions within the N-terminal region, the second wing, and the third helix (11). FOXOs can function both as transcriptional activators and repressors, probably depending on the range of associated cofactors that they recruit upon DNA binding. Growth factors, cytokines, and hormones negatively regulate FOXO transcriptional activity through inhibitory phosphorylation predominantly mediated by protein kinase $B$ (PKB/c-akt) (13, 54). This phosphorylation inactivates FOXOs by recruiting 14-3-3 proteins, which prevent DNA binding and inhibit nuclear import (Fig. 2) [reviewed in (68)]. In addition to $\mathrm{PKB}$, several other protein kinases have been identified that induce the cytoplasmic relocalization of FOXOs, including serum- and glucocorticoid-inducible kinase, cyclin-dependent kinase-2 (CDK2), and $\mathrm{I} \kappa \mathrm{B}$ kinase $(14,40,41)$.

Deletion of the Foxo alleles in mice has revealed both redundant as well as isoform specific functions of FOXO1, FOXO3, and FOXO4 (Table 1). Deletion of Foxo1 is lethal due to incomplete vascular development (39). However, Foxo3 $^{-/-}$mice were found to be viable, but exhibited lymphoproliferation and widespread organ inflammation due to hyperactivated helper T cells (56). Further examination in female mice revealed an age-dependent infertility due to global ovarian follicle activation, resulting in early oocyte depletion $(16,39)$. In contrast, for Foxo $4^{-/-}$mice no phenotype has yet been detected (39). The recent generation of

\footnotetext{
${ }^{1}$ Molecular Immunology Lab, Department of Immunology, University Medical Center Utrecht, Utrecht, The Netherlands.

${ }^{2}$ Department of Pediatric Immunology, University Medical Center Utrecht, Utrecht, The Netherlands.
} 


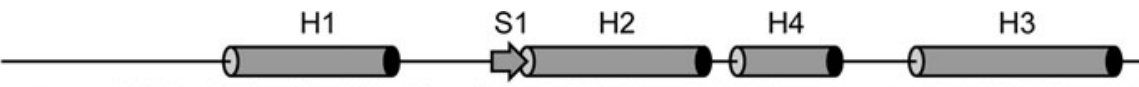

FOXO1 KSSSSRRNAWGNLSYADLITKAIESSAEKRLTLSQIYEWMVKSVPYFKDKGDSNSSAGWKNSIRHNLSLH FOXO3 RKCSSRRNAWGNLSYADLITRAIESSPDKRLTLSQIYEWMVRCVPYFKDKGDSNSSAGWKNSIRHNLSLH FOXO4 KGGS-RRNAWGNQSYAELISQAIESAPEKRLTLAQIYEWMVRTVPYFKDKGDSNSSAGWKNSIRHNLSLH FOXO6 AK-SSRRNAWGNLSYADLITKAIESAPDKRLTLSQIYDWMVRYVPYFKDKGDSNSSAGWKNSIRHNLSLH DAF-16 QLAQKKPNPWGEESYSDIIAKALESAPDGRLKLNEIYQWFSDNIPYFGERSSPEEAAGWKNSIRHNLSLH FOXA1 TFKRSYPHAKPPYSYISLITMAIQQAPSKMLTLSEIYQWIMDLFPYYRQNQQR------WQNSIRHSLSFN

SKFIRVQN--EGTGKSSWWMLNPEG--GKSGKSPRRRAASMDNN
SRFMRVQN--EGTGKSSWWIINPDG--GKSGKAPRRRAVSMDNS
SKFIKVHN--EATGKSSWWMLNPEG--GKSGKAPRRRAASMDSS
TRFIRVQN--EGTGKSSWWMLNPEG--GKTGKTPRRRAVSMDNG
SRFMRIQN--EGAGKSSWWVINPDAKPGRNPRRTRERSNTIETT
DCFVKVARSPDKPGKGSYWTLHPDS----- S3

an inducible Foxo1 ${ }^{-/-}$, Foxo $3^{-/-}$, and Foxo4 $4^{-/-}$mouse model has revealed redundant roles for FOXOs in both oncogenesis and stem cell homeostasis. Conditional deletion of Foxo1, Foxo3, and Foxo4 results in the development of lymphoblastic thymic lymphomas and hemangiomas, demonstrating that FOXOs act as true functional tumor suppressors (72). Analysis of the hematopoietic system after loss of Foxo1, Foxo3, and Foxo4 revealed increased numbers of myeloid progenitors in peripheral blood, whereas in the bone marrow the number of hematopoietic stem cells (HSCs) was reduced. Further analysis revealed that FOXOs were required for HSC renewal by decreasing levels of reactive oxygen species (ROS) (99). Further, conditional deletion of Foxo1, Foxo3, and Foxo4 has a similar effect on neural stem cells (NSCs) (71). Foxo-deficient mice demonstrated a decline in the NSC pool, due to increased proliferation and loss of self-renewal, indicating that FOXOs may play a critical general role in stem cell homeostasis. Surprisingly, similar effects have also revcently been reported in mice deficient for Foxo3 (80).

Over the last decade, a plethora of studies have demonstrated that FOXOs play critical roles in a wide variety of cellular processes, including proliferation, apoptosis, autophagy, metabolism, inflammation, differentiation, and stress resistance (Table 2). This review focuses on the functional consequences of FOXO activation based on our current knowledge of regulation of transcriptional targets.

\section{Regulation of Proliferation Through Induction of Cell Cycle Arrest}

One of the functions initially attributed to FOXO activation is the regulation of cell cycle progression (Fig. 3). FOXOs have been shown to modulate both the G1-S transition and the G2-M phase by coordinating expression of multiple important cell cycle regulators [reviewed in (38)]. Ectopic expression of constitutively active $\mathrm{FOXO} 4$, in which the inhibitory phosphorylation sites are mutated, induces a G1 cell cycle arrest in A14, U2OS, and Jurkat cells, which is dependent on expression of the cell cycle inhibitor p27 (61). The cell cycle is regulated by the coordinated activation of multiple cyclin/CDKs, which phosphorylate and regulate multiple substrates that are essential for cell cycle progression. p27 is a member of the Cip/Kip family of CDK inhibitors together with p21 and p57 and binds to both cyclin and CDK subunits inhibiting the activities of cyclin D-, E-, and A-CDK complexes [reviewed in (8)]. Use of promoter luciferase reporter assays demonstrated that p27 expression was regulated through direct FOXO4-mediated transcription (61). Cytokines are regulators of proliferation and survival of hematopoietic cells and cytokine deprivation will often result

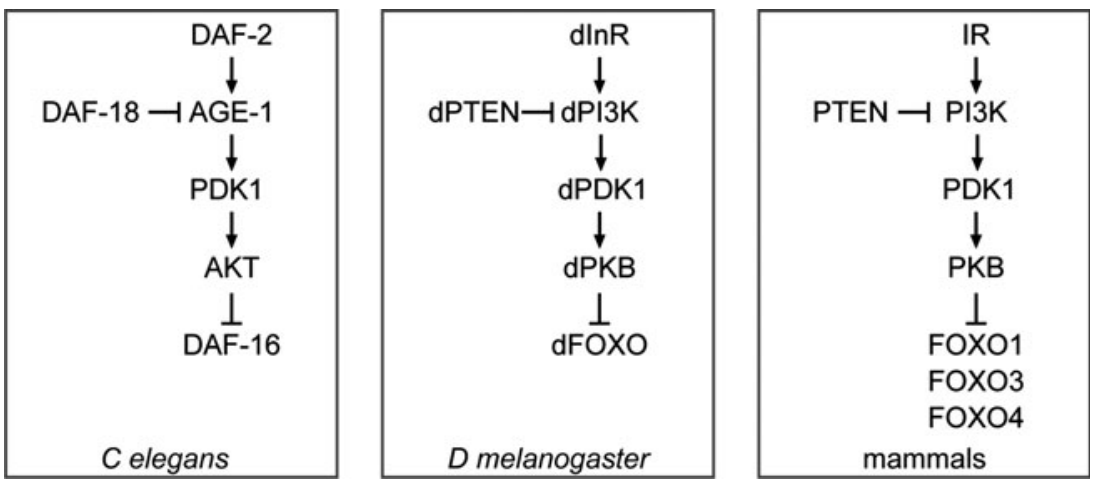

FIG. 2. Regulation of FOXOs is conserved between Caenorhabditis elegans, Drosophila melanogaster, and mammals. Activation of the insulin receptor (DAF-2) activates PI3K (AGE-1) resulting in the formation of $\mathrm{PIP}_{3}$. These phosphorylated lipids form docking sites for PDK1 and PKB (AKT) resulting in their activation. PKB phosphorylates and inhibits FOXO transcription factors. While $C$. elegans and $D$. melanogaster have a single FOXO isoform, in mammals three distinct FOXOs are regulated by PKB: FOXO1, FOXO3, and FOXO4. PDK1, 3-phosphoinositidedependent kinase 1; PI3K, phosphatidylinositol-3-kinase; PKB, protein kinase B. 
Table 1. Phenotypes of Forkhead Box O Knockout Mice

\begin{tabular}{|c|c|c|}
\hline Hosaka et al. (39) & Foxo1 ${ }^{-1-}$ & Lethal due to incomplete vascular development \\
\hline Nakae et al. (64) & Foxo1 ${ }^{-1+}$ & Restored insulin sensitivity and rescued diabetic phenotype in InsR mutant mice \\
\hline Kitamura et al. (52) & Foxo1 ${ }^{-1+}$ & Reversed $\beta$-cell failure in mice lacking Insulin receptor substrate $2\left(\operatorname{Irs} 2^{-/-}\right.$) \\
\hline Castrillon et al. (16) & Foxo3 ${ }^{-1-}$ & $\begin{array}{l}\text { Age-dependent infertility due to global ovarian follicle activation resulting in } \\
\text { early oocyte depletion }\end{array}$ \\
\hline \multicolumn{3}{|r|}{ ( } \\
\hline Lin et al. (56) & Foxo3 ${ }^{-1-}$ & $\begin{array}{l}\text { Lymphoproliferation and widespread organ inflammation due to hyperactivated } \\
\text { helper T cells }\end{array}$ \\
\hline Renault et al. (80) & Foxo3 ${ }^{-1-}$ & $\begin{array}{l}\text { Decline in neural stem cell pool due to increased proliferation and loss } \\
\text { of self-renewal }\end{array}$ \\
\hline Hosaka et al. (39) & Foxo4 $4^{-1-}$ & No phenotype detected yet \\
\hline Paik et al. (72) & $\begin{array}{l}\text { Foxo1 } 1^{-/-}, \text {Foxo3 }^{-/-} \\
\text {Foxo4 }\end{array}$ & $\begin{array}{l}\text { Uterine hemangiomas appear at } 6-8 \text { weeks of age, which progress to massive } \\
\text { fatal hemaningiomas affecting numerous tissues. Lymphoblastic thymic } \\
\text { lymphomas appear at } 19-30 \text { weeks of age }\end{array}$ \\
\hline Tothova et al. (99) & $\begin{array}{l}\text { Foxo1 } 1^{-/-}, \text {Foxo3 }^{-/-} \\
\text {Foxo4 }\end{array}$ & $\begin{array}{l}\text { Decrease in long-term hematopoietic stem cell population due to increased } \\
\text { entry into cell cycle, decreased renewal capacity, increased apoptosis, which } \\
\text { are caused by an increase in reactive oxygen species }\end{array}$ \\
\hline Paik et al. (71) & $\begin{array}{l}\text { Foxo1 } 1^{-/-}, \text {Foxo3 }^{-1-}, \\
\text { Foxo } 4^{-/-}\end{array}$ & $\begin{array}{l}\text { Decline in neural stem cell pool due to increased proliferation and loss } \\
\text { of self-renewal }\end{array}$ \\
\hline
\end{tabular}

Deletion of specific FOXO genes in mice has revealed both redundant and nonredundant effects.

FOXO, Forkhead box O.

in arrest in the G1 phase of the cell cycle. Several reports have shown that cytokine deprivation induces the activation of FOXO3, resulting in an subsequent increase in p27 expression and a cell cycle arrest $(24,37,92)$. Activation of a conditional FOXO3 mutant in bone marrow-derived $\mathrm{Ba} / \mathrm{F} 3$ cells was found to result in increased transcription of the p27 gene, which was associated with a cell cycle arrest, indicating that FOXO3 activation is sufficient for p27 upregulation and inhibition of proliferation (24). In addition to regulation of p27 expression levels, FOXOs have been shown to regulate the transcription of another Cip/Kip family member, namely, p21. Transforming growth factor $\beta$ can block proliferation of epithelial, neuronal, and immune cells by activating Smad transcription factors that regulate expression of multiple cell cycle regulators, including p21 (88). Immunoprecipitation experiments demonstrated that Smad3 and Smad4 can bind to the DNA binding domain of FOXO1, FOXO3, and FOXO4 (88). Further, in epithelial cells Smads increase p21 expression by forming a complex with FOXOs (88). The p21 promoter contains both FOXO and Smad enhancer elements, which are both required for the induction of $\mathrm{p} 21$ expression by transforming growth factor $\beta$. In addition, activation of the phosphatidylinositol-3-kinase (PI3K) pathway and consequently inactivation of FOXOs is sufficient to block p21 transcription (88). Nakae et al. have shown that the regulation of p21 expression by FOXO1 also plays an important role in the proliferation of adipocytes. In these cells insulin signaling repressed the upregulation of p21 expression, resulting in increased proliferation, whereas in the absence of insulin, FOXO1 activation results in increased p21 expression and a cell cycle arrest (65).

Besides regulation of p21 and p27, FOXOs have been described to regulate expression of $\mathrm{p} 15$ and p19, CDK inhibitors of the INK4 family. These cell cycle inhibitors inhibit the cyclin $\mathrm{D} / \mathrm{CDK}$ complex by binding to CDK4 and CDK6, thereby blocking the binding of cyclin D (8). FOXO1 and FOXO3 have both been reported to upregulate expression of $\mathrm{p} 15$ and $\mathrm{p} 19$ by directly binding to FOXO enhancer elements present in their promoters (47). Moreover, mouse embryonic fibroblasts from p15 or p19-null mouse failed to arrest in G1 after incubation with the PI3K inhibitor LY294002, indicating that expression of both p15 and p19 is required for cell cycle arrest (47). These results are perhaps surprising since previous reports have shown that the increased p27 expression by FOXOs is also itself sufficient for cell cycle arrest (23). A possible explanation for this is that $\mathrm{p} 27$ requires a low level of $\mathrm{p} 15$ or $\mathrm{p} 19$ expression to block the cyclin-D/CDK complex.

Besides regulation of CDK inhibitors, FOXOs have been described to block cell cycle progression by directly regulating expression of cyclin D, cyclin G, and the retinoblastoma protein family member $\mathrm{p} 130$. Overexpression of cyclin D1 partially rescues FOXO4-induced cell cycle arrest, suggesting that the effect of FOXO4 on proliferation depends on the repression of cyclin D expression and a decrease in cyclin D/CDK activity (84). However, overexpression of cyclin D1 may also act to titrate away CDK inhibitors such as p21 and p27, thereby affecting cylin-CDK activity indirectly. p130 is a member of the retinoblastoma protein family which represses the activity of E2F transcription factors and thereby regulates expression of genes required for $\mathrm{S}$ phase entry, such as cyclin A and cyclin E (95). FOXO4 can upregulate p130; however, the functional consequences of this regulation remain unclear (54). Cyclin G2 and p130 levels are high in resting B cells, whereas mitogen stimulation induces a rapid decrease in their expression (17). Activation of $\mathrm{FOXO} 3$ has been reported to induce cell cycle arrest in murine $B$ cells and increase expression of cyclin G2. In addition, overexpression of cyclin G2 results in a block in cell cycle progression, demonstrating that FOXOs regulate lymphocyte quiescence through regulation of multiple cell cycle regulators (17).

\section{Regulation of Genes Involved in Stress Resistance}

In the nematode worm C. elegans inactivation of the insulin pathway through nutrient-deprivation induces dauer formation, a stress-resistant state in which the worm lowers it metabolism and has an increased lifespan (50). Genetic analysis has revealed that the $C$. elegans forkhead transcription factor DAF-16 is inhibited by insulin signaling and that its activity is 
Table 2. Forkhead Box O Transcriptional Targets

\begin{tabular}{|c|c|c|c|c|}
\hline Target & $\begin{array}{c}\text { Up-or } \\
\text { downregulation }\end{array}$ & FOXO & Pathway & References \\
\hline Cyclin D & - & FOXO3, FOXO4 & Cell cycle & 84 \\
\hline Cyclin G2 & + & FOXO1, FOXO3, FOXO4 & Cell cycle & 17,58 \\
\hline P130 & + & FOXO1, FOXO3, FOXO4 & Cell cycle & 17,54 \\
\hline P15 & + & FOXO1, FOXO3 & Cell cycle & 47 \\
\hline P19 & + & FOXO1, FOXO3 & Cell cycle & 47 \\
\hline P21 & + & FOXO1,FOXO3,FOXO4 & Cell cycle & 65,88 \\
\hline P27 & + & FOXO1, FOXO3, FOXO4 & Cell cycle & $24,61,92$ \\
\hline Plk & + & FOXO1 & Cell cycle & 106 \\
\hline Manganese superoxide dismutase & + & FOXO3 & Stress resistance & 53 \\
\hline catalase & + & FOXO3 & Stress resistance & 66 \\
\hline Peroxiredoxin III & + & FOXO3 & Stress resistance & 18 \\
\hline Sterol carrier protein & + & FOXO3 & Stress resistance & 21 \\
\hline Gadd45 & + & FOXO3, FOXO4 & DNA repair & 30,100 \\
\hline Bim & + & FOXO3 & Apoptosis & 23,33 \\
\hline Fasl & + & FOXO1, FOXO3 & Apoptosis & 13,19 \\
\hline $\begin{array}{l}\text { Tumor necrosis factor } \\
\text { receptor-associated death domain }\end{array}$ & + & FOXO1 & Apoptosis & 81 \\
\hline $\begin{array}{l}\text { Tumor necrosis factor-related } \\
\text { apoptosis inducing ligand }\end{array}$ & + & FOXO1, FOXO3 & Apoptosis & 63 \\
\hline $\begin{array}{l}\text { p53 upregulated modulator } \\
\text { of apoptosis }\end{array}$ & + & FOXO3 & Apoptosis & 105 \\
\hline $\mathrm{Bcl} 6$ & + & $\mathrm{FOXO} 3, \mathrm{FOXO} 4$ & Apoptosis & 28,98 \\
\hline PTEN-induced kinase 1 & + & FOXO3 & Apoptosis & 62 \\
\hline Glucose-6-phosphatase & + & FOXO1, FOXO3 & Metabolism & 69,78 \\
\hline Phosphoenolpyruvate carboxykinase & + & FOXO1 & Metabolism & 86 \\
\hline PGC1 & + & FOXO1 & Metabolism & 20 \\
\hline adiponectin & + & FOXO1 & Metabolism & 79 \\
\hline Agouti-related protein & + & FOXO1 & Metabolism & 49,51 \\
\hline proopiomelanocortin & - & FOXO1 & Metabolism & 49,51 \\
\hline neuropeptide $Y$ & + & FOXO1 & Metabolism & 49 \\
\hline Apoliprotein C-III & + & FOXO1 & Metabolism & 2 \\
\hline $\operatorname{Pdx} 1$ & - & FOXO1 & Metabolism & 52 \\
\hline B-cell translocation gene 1 & + & FOXO3 & Differentiation & 5 \\
\hline Id1 & - & FOXO3 & Differentiation & 10 \\
\hline Atrogin-1 & + & FOXO3 & Muscle atrophy & 83 \\
\hline Bnip3 & + & FOXO3 & Muscle atrophy & 57,107 \\
\hline LC3 & + & $\mathrm{FOXO3}$ & Muscle atrophy & 57,107 \\
\hline Garabl12 & + & $\mathrm{FOXO3}$ & Muscle atrophy & 107 \\
\hline Interleukin 7R & + & FOXO1 & Inflammation & 70 \\
\hline $\mathrm{C} / \mathrm{EBP} \beta$ & + & FOXO1 & Inflammation & 43 \\
\hline Interleukin $1 \beta$ & + & FOXO1 & Inflammation & 94 \\
\hline 4E binding protein 1 & + & FOXO1, FOXO3 & Insulin signaling & 76 \\
\hline InsR & + & FOXO1 & Insulin signaling & 77 \\
\hline trible 3 & - & FOXO1 & Signaling & 59 \\
\hline Caveolin-1 & + & FOXO1, FOXO3, FOXO4 & Signaling & 82,102 \\
\hline Protein phosphatase 2A & - & FOXO1 & Signaling & 67 \\
\hline FOXO1 & + & FOXO1, FOXO3 & Signaling & 27 \\
\hline $\mathrm{FOXO3}$ & + & FOXO1, FOXO3 & Signaling & 27 \\
\hline $\mathrm{P} 110 \alpha$ & + & FOXO3 & Signaling & 42 \\
\hline Collagenase & + & FOXO3 & $\begin{array}{l}\text { Extracellular matrix } \\
\text { degradation }\end{array}$ & 60 \\
\hline Matrix metalloproteinase 9 & + & FOXO4 & $\begin{array}{l}\text { Extracellular matrix } \\
\text { degradation }\end{array}$ & 55 \\
\hline Mxi1 & + & FOXO3 & Tumor suppression & 22 \\
\hline Estrogen receptor $\alpha$ & + & $\mathrm{FOXO3}$ & Tumor suppression & 35 \\
\hline Myostatin & + & FOXO1 & Differentiation & 1 \\
\hline Endothelial nitric oxide synthase & - & FOXO1, FOXO3 & Vessel formation & 75 \\
\hline Multidrug resistance protein 1 & + & FOXO1 & Drug resistance & 36 \\
\hline $\mathrm{CBP} / \mathrm{p} 300$ interacting transactivator 2 & + & FOXO3 & Angiogenesis & 6 \\
\hline
\end{tabular}

Listed are transcriptional targets that have been reported to be directly regulated by FOXO1, FOXO3, or FOXO4. FOXO target genes are grouped by cellular function. The effect of FOXO activation on the expression level: upregulation and downregulation are indicated by - and + , respectively. 


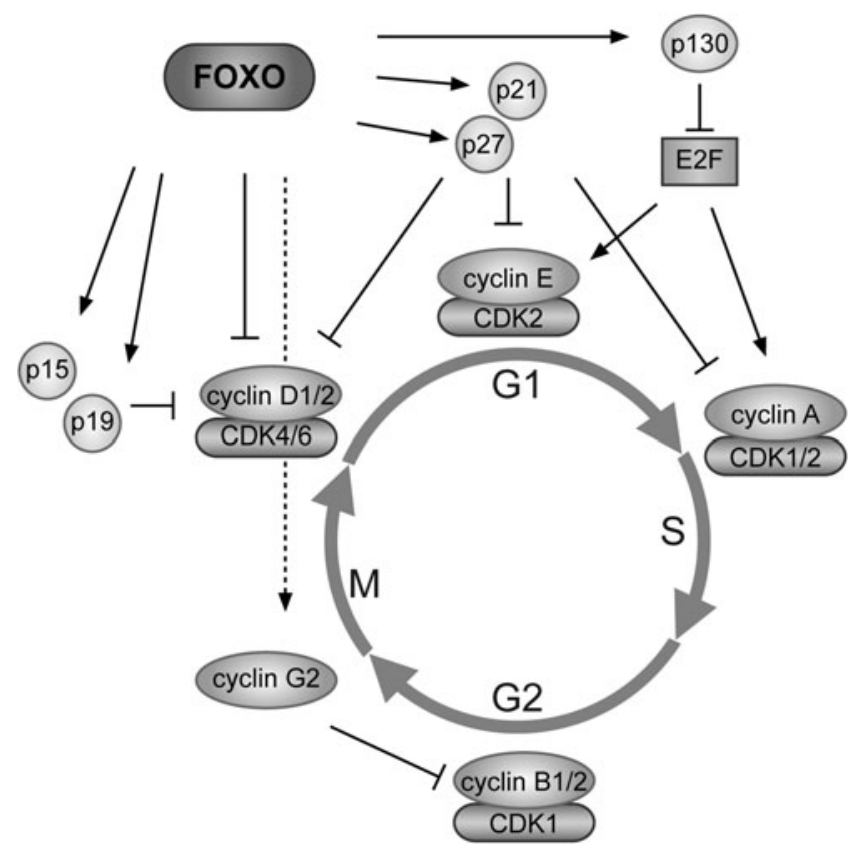

FIG. 3. Regulation of cell cycle progression by FOXOs. FOXOs can inhibit proliferation during distinct phases of the cell cycle. FOXOs block $S$ phase entry and cause a G1 cell cycle arrest by upregulation of the cell cycle inhibitors p15, p19, p21, and p27, downregulation of cyclin D and upregulation of p130. See Regulation of Proliferation Through Induction of Cell Cycle Arrest for further explanation.

required for lifespan extension in insulin receptor mutants (48). DAF-16 exerts its effect on lifespan through regulation of genes involved in microbial defense, cellular stress response, and metabolism [reviewed in (74)].

In humans accumulation of cellular damage by oxidative stress has been implicated in oncogenesis and aging (29). FOXOs have been suggested to protect cells from oxidative damage by increasing transcription of multiple genes regulating scavenging of ROS. Activation of FOXO3 either by treatment with the PI3K inhibitor LY294002 or by activating a conditional active FOXO3 mutant increases expression of manganese superoxide dismutase (MnSOD) in a colon carcinoma cell line through direct binding to its promoter (53). MnSOD protects against oxidative damage through conversion of superoxide, which is formed as a by-product during generation of ATP in mitochondria, into hydrogen peroxide. Activation of FOXO3 was subsequently found to rescue glucose-deprived cells from mitochondrial damage in wild-type mouse embryonic fibroblasts but not in MnSOD deficient mouse embryonic fibroblasts, demonstrating that the FOXO3induced MnSOD expression is a requirement for cell survival after nutrient deprivation (53). In addition to regulation of MnSOD, FOXO3 also regulates catalase expression, another antioxidant enzyme catalyzing the conversion of hydrogen peroxide to water and oxygen. In the neuronal cell line PC12, increased catalase expression by FOXO3 was found to decrease oxidative stress resulting in increased cell survival (66). Thus, through coordinated regulation of MnSOD and catalase expression FOXOs are able to decrease oxidative damage and thereby increase cellular survival.

Experiments in human cardiac fibroblasts have revealed that FOXOs can also modulate the cellular response to hydrogen peroxide by expression of peroxiredoxin III, an antioxidant enzyme (18). Knockdown of FOXO3 in these cells demonstrated that expression of peroxiredoxin III was dependent on FOXO3, and FOXO3 was shown to bind to the peroxiredoxin III promoter. While the accumulation of hydrogen peroxide and the percentage of apoptotic cells in response to serum starvation was increased after peroxiredoxin III knockdown, concomitant FOXO3 knockdown resulted in even higher levels of hydrogen peroxide, suggesting that multiple FOXO targets are important for resistance to oxidative stress (18).

Conditional deletion of Foxo1, Foxo3, and Foxo4 in the mouse hematopoietic system has further highlighted the physiological importance of regulation of ROS in vivo (99). Analysis of hematopoietic cells in the bone marrow showed that Foxo-deficient mice had reduced numbers of HSCs, whereas the number of myeloid progenitors in peripheral blood was increased, suggesting that FOXOs are important for maintaining HSCs in a quiescent state. Repopulation experiments demonstrated decreased repopulating ability of bone marrow cells from Foxo-deficient mice, indicating that FOXO activity is required for stem cell self-renewal. In HSCs isolated from Foxo-deficient mice, the levels of ROS were significantly increased and treatment of these animals with the antioxidant $\mathrm{N}$-acetyl-cysteine was sufficient to rescue the Foxo $^{-1-}$ HSC phenotype (99). These observations indicate that FOXO-mediated resistance to oxidative stress is critical for homeostasis of the HSC compartment in vivo.

In addition to reducing oxidative damage by decreasing the availability of ROS, FOXOs also protect cells from DNA damage by increasing DNA repair. Upon expression of a constitutively active FOXO3 mutant, Rat1 fibroblasts show a $\mathrm{G}_{2}-\mathrm{M}$ delay after release from a chemically induced S-phase block (100). The $\mathrm{G}_{2}-\mathrm{M}$ checkpoint is activated after DNA damage, which halts the cell cycle providing time for repair before continuing with cell division. The FOXO3-induced $\mathrm{G}_{2^{-}}$ $\mathrm{M}$ arrest suggested a role for FOXO in DNA damage repair. Indeed, ectopic expression of a constitutive active FOXO3 mutant increased activity of a UV-damaged luciferase reporter construct, suggesting that FOXO3 can indeed modulate DNA damage repair mechanisms (100). Microarray analysis subsequently identified growth arrest and DNA damage response gene GADD45 as a novel FOXO transcriptional target. Gadd45 has been shown to participate in cell cycle arrest, DNA repair, and survival in response to stress. Activation of FOXO3 increased expression of Gadd45 on both the mRNA and protein level. Importantly, the FOXO3-induced DNA damage repair was compromised in Gadd $45^{-/-}$cells, suggesting that Gadd45 expression is required for FOXO3-mediated DNA repair (100).

While high levels of ROS are detrimental to cellular survival, low levels of ROS are often required for intracellular signaling by acting as secondary messengers [reviewed in (93)]. Stimulation of cultured neonatal rat cardiomyocytes with insulin increases the intracellular concentration of ROS and results in an increase in cell size (97). This insulin-induced hypertrophy can be inhibited by the antioxidant NAC, suggesting that insulin can regulate cell size by increasing ROS levels. The increase of ROS levels observed after insulin stimulation correlate with a reduction in FOXO3 phosphorylation and decreased expression of the antioxidant enzyme catalase. Further, knockdown of FOXO3 was sufficient to induce hypertrophy and could be abrogated by ectopic expression of catalase, suggesting that insulin signaling induces ROS-mediated 
hypertrophy by inhibiting FOXO3 function (97). In patients with heart failure, high insulin levels in plasma are associated with cardiac hypertrophy (73). The repression of cell size in cardiomyocytes by FOXO3 suggests that insulin-mediated inhibition of FOXO3 might thus play a role in heart failure in vivo.

\section{Life and Death Decisions}

Programmed cell death, also known as apoptosis, can be induced by activation of either intrinsic or extrinsic pathways. In the extrinsic pathway binding of death receptor ligands to their receptors triggers the formation of a death-inducing signaling complex and consequently activation of caspases [reviewed in (34)]. In contrast, intracellular stress can induce apoptosis by activating pro-apoptotic B-cell lymphoma 2 (Bcl2) proteins, which modulate release of cytochrome $c$ from mitochondria, resulting in caspase- 9 activation and subsequently activation of downstream effector caspases, which execute the apoptotic program [reviewed in (12)].

FOXOs were first reported to be required for the induction of apoptosis after growth factor withdrawal in hematopoietic and neuronal cells. FOXOs can activate the intrinsic apoptotic pathway through upregulation of multiple pro-apoptotic Bcl2 family members, whereas upregulation of death receptor ligands can activate the extrinsic pathway (Fig. 4). Cytokine deprivation or conditional FOXO3 activation in bone marrowderived $\mathrm{Ba} / \mathrm{F} 3$ cells results in cytochrome $\mathrm{c}$ release, caspase activation, and DNA laddering, subsequently resulting in induction of apoptosis (23). FOXO3 was found to directly

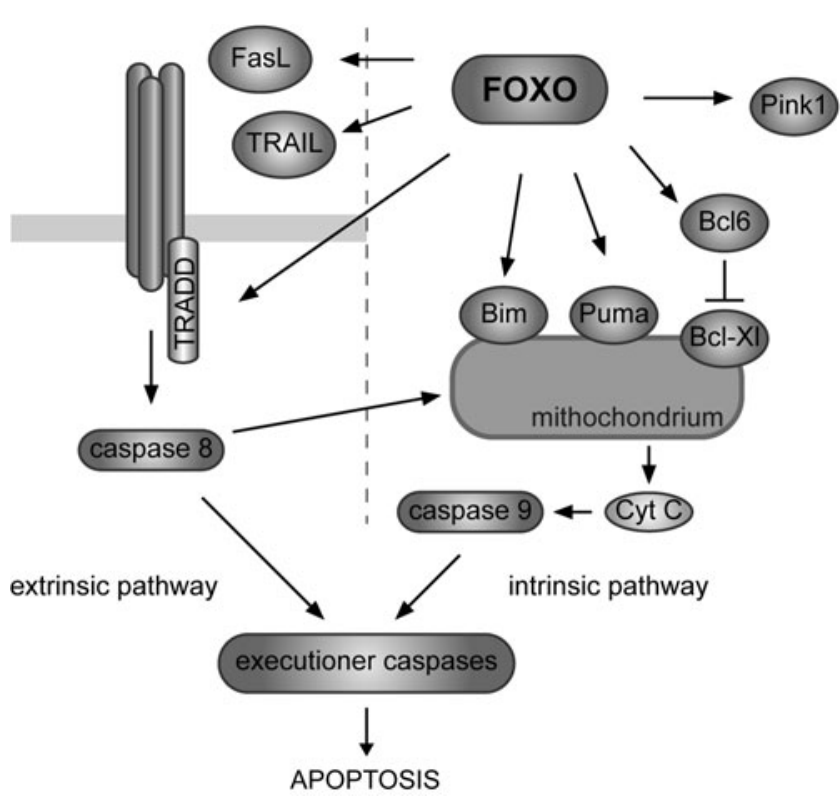

FIG. 4. Regulation of apoptosis by FOXOs. FOXOs can induce apoptosis by regulating expression of multiple proand antiapoptotic proteins. Upregulation of the death receptor ligands FasL and TRAIL will induce apoptosis through activation of the extrinsic apoptotic pathway. While regulation of expression of Bim, Puma, BclXl, and Pink1 by FOXOs can induce apoptosis via the mitochondria-dependent intrinsic pathway. See Life and Death Decisions for further explanation. FasL, Fas-ligand; Pink1, PTEN-induced kinase 1; Puma, p53 upregulated modulator of apoptosis; TRAIL, tumor necrosis factor-related apoptosis inducing ligand. upregulate expression of the pro-apoptotic Bcl-2 family member Bim, and overexpression of Bcl-2 rescued cells from FOXO3-induced apoptosis (23). Stahl et al. demonstrated that the regulation of Bim expression by FOXO3 also plays an important role in the survival of activated T cells (92). A recent report demonstrated that $\mathrm{FOXO} 3$ also increases expression of the pro-apoptotic Bcl-2 family member p53 upregulated modulator of apoptosis (Puma) after interleukin (IL)-2 withdrawal (105). T cells derived from $\mathrm{Bim}^{-/-}$and $\mathrm{Puma}^{-/-}$mice were resistant to apoptosis after IL-2 deprivation, demonstrating that regulation of both $\mathrm{Bcl}-2$ proteins by $\mathrm{FOXO} 3$ is important for the induction of apoptosis in the absence of cytokines (105). The induction of Bim expression by FOXO also plays a role in the induction of neuronal apoptosis during embryogenesis. Using sympathetic neurons, which depend on nerve growth factor as a model, inhibition of FOXO activity was found to delay nerve growth factor withdrawalinduced death (33). Ectopic expression of FOXO3 induced apoptosis, which was itself dependent on Bim expression (33). Additionally, FOXO4 can induce apoptosis through upregulation of the transcriptional repressor Bcl-6 (98). Promoter reporter analysis has demonstrated that Bcl-6 itself can subsequently downregulate expression of the antiapoptotic protein B-cell lymphoma extra large (98). Taken together, these studies show that FOXO3 can induce apoptosis by activation of the intrinsic apoptotic pathway through modulation of expression of several Bcl-2 family members.

PTEN-induced kinase 1 (Pink1) was originally identified as a PTEN-induced transcript, and mutations in this gene have been linked with autosomal recessive Parkinson's disease (101). Pink1 has been linked with survival of neuronal cells and loss of PINK1 expression is associated with dysregulated mitochondrial function; however, the precise mechanisms how Pink1 exerts its functions remain unclear (15). Recently, it was reported that in T cells Pink1 mRNA expression is increased by either cytokine starvation or ectopic expression of FOXO3 (62). Promoter reporter assays and ChIP analysis revealed that FOXO3 can directly regulate PINK1 expression through binding to its promoter. Further, depletion of PINK1 by siRNAmediated knockdown sensitized cells to IL-2 withdrawalinduced cell death, suggesting that in lymphocytes regulation of Pink1 expression by FOXOs is important in modulating cellular survival after growth factor deprivation (62).

One of the first reported transcriptional targets for FOXO was Fas-ligand (FasL), which can induce cell death in neuronal and lymphoid cells (13). Ectopic expression of a constitutively active FOXO3 mutant was found to increase FasL promoter activity in reporter assays. Further, Jurkat cells that were deficient in components of the Fas signaling cascade failed to undergo apoptosis after expression of FOXO3, indicating that the Fas-mediated signaling is required for induction of apoptosis by FOXO3 (13). Overexpression of FOXO1 and FOXO3 in prostate carcinoma cells also induces apoptosis and this correlates with upregulation of tumor necrosis factorrelated apoptosis inducing ligand (63). Utilizing promoter reporter assays, it was also shown that tumor necrosis factorrelated apoptosis-inducing ligand is a direct transcriptional target of FOXOs (63).

Rodukai et al. have demonstrated that treatment of lung cancer cells with a 3-phosphoinositide-dependent kinase 1 inhibitor sensitized the cells to chemotherapeutic druginduced apoptosis (81). Further experiments revealed that the 
3-phosphoinositide-dependent kinase 1 inhibitor resulted in activation of FOXO1 and increased expression of tumor necrosis factor receptor-associated death domain (TRADD). FOXO1 was shown to directly regulate expression of TRADD through binding to a conserved FOXO enhancer element in the promoter of the TRADD gene. Ectopic expression of a TRADD mutant lacking the death domain attenuated chemotherapeutic drug-induced cell death, demonstrating the importance of this FOXO target gene in regulating apoptosis (81).

While most studies report that activation of FOXOs induces cell cycle arrest and induction of apoptosis, a study by Jonsson et al. suggests that FOXOs may also increase cellular survival through repression of FasL expression (46). In a murine model for rheumatoid arthritis, loss of Foxo3 expression protected against immune complex-mediated inflammation. Administration of serum from arthritic mice to healthy littermates caused a severe inflammatory arthritis, whereas Foxo3deficient mice were resistant to this. Adoptive transfer of wildtype neutrophils to Foxo $3^{-/-}$mice restored their susceptibility to arthritis, indicating that the resistance to induction of arthritis is caused by an intrinsic neutrophil defect. Neutrophils isolated from FOXO3 deficient mice showed higher levels of apoptosis than wild-type cells. After stimulation with inflammatory cytokines, Foxo3-deficient neutrophils also showed high levels of FasL expression, suggesting that Foxo3 represses FasL expression in neutrophils. Further, transfection of a FasL reporter in neutrophils demonstrated that Foxo3 can indeed downregulate FasL promoter activity (46). This is in contrast to the previous studies described above, and it is possible that FOXOs may interact with alternative cofactors in neutrophils, resulting in suppression of FasL promoter activity.

\section{The Role of FOXO1 in Glucose Metabolism and Diabetes}

Insulin receptor signaling results in PKB-mediated inactivation of FOXOs, a pathway that is evolutionary conserved. In mammals, regulation of insulin levels ensures glucose homeostasis by modulating glucose production as well as glucose uptake by peripheral tissue. FOXO1 is highly expressed in insulin responsive tissues and has been shown to play an important role in metabolic changes during adaptation to fasting $(2,3,78)$. Generation of Foxo1 $1^{-/+}$mice has highlighted the importance of FOXO1 in the development of type 2 diabetes. Deletion of one Foxo1 allele restored insulin sensitivity and rescued diabetic phenotype in insulin receptor mutant mice (64).

Activation of FOXO1 in the liver after decreased insulin signaling increases gluconeogenesis, whereas in the pancreas FOXO1 is an important regulator of proliferation and beta cell function (Fig. 5) (52). During fasting, the upregulation of gluconeogenic genes in the liver, such as glucose-6-phosphatase (G6Pase) and phosphoenolpyruvate carboxykinase (PEPCK), ensures a stable blood glucose level (7). Insulin blocks gluconeogenesis in the liver through inhibition of the transcription of these enzymes. Puigserver et al. have shown that FOXO1 increases G6Pase expression in mouse hepatocytes, which can be inhibited by insulin (78). This regulation of G6Pase expression requires the liver specific transcription factor PGC1. Both FOXO1 and PGC1 associate with the G6Pase promoter, and expression of both factors showed a synergistic effect on G6Pase mRNA expression. This PGC1-FOXO1 complex is

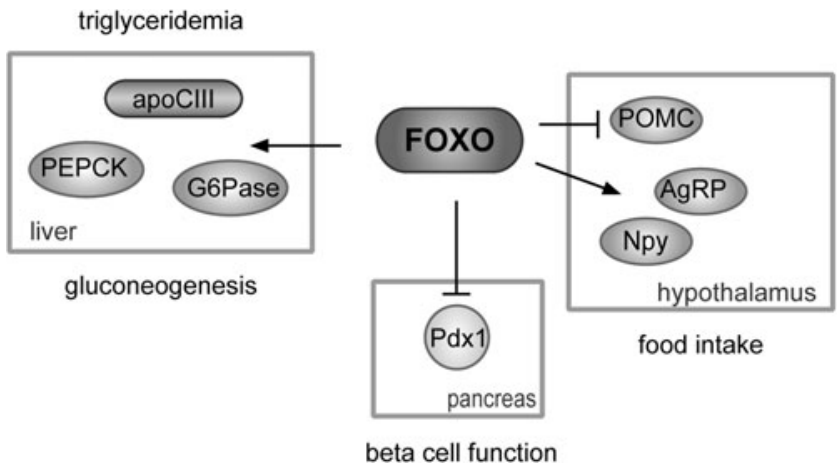

FIG. 5. Role of FOXO1 in metabolism. FOXO1 plays an important role in regulating cellular metabolic activity through upregulation of genes in the liver involved in gluconeogenesis including PEPCK and G6Pase and lipid metabolism such as apoCIII. FOXO1 is also involved in $\beta$-cell function in the pancreas by suppressing $P d x 1$, whereas regulation of POMC, Agrp, and Npy in the hypothalamus regulates food intake. See The Role of FOXO1 in Glucose Metabolism and Diabetes for further explanation. Agrp, Agouti-related protein; G6Pase, glucose-6-phosphatase; PEPCK, phosphoenolpyruvate carboxykinase; POMC, pro-opiomelanocortin.

disrupted after PKB-mediated phosphorylation of FOXO1 in response to insulin, resulting in decreased G6Pase expression. Further, injection of mice with an adenoviral vector expressing a dominant negative FOXO1 mutant inhibited the induction of G6Pase by PGC1 in the liver (78). In addition, FOXO1 can also regulate expression of PGC1 itself, thereby regulating PEPCK and G6Pase expression levels indirectly (20). It has been suggested that the regulation of G6Pase and PEPCK by FOXO1 plays an important role in the development of type 2 diabetes. FOXO1 expression in the liver is increased in diabetic mice, and this is associated with increased expression of PEPCK and G6Pase (3). Inhibition of Foxo1 activity by expression of a dominant negative FOXO1 mutant decreased both PEPCK and G6Pase expression and returned blood glucose levels to normal levels (3). Further, expression of FOXO1 was found to be increased during differentiation of fetal liver cells, correlating with increased G6Pase and PEPCK mRNA levels (86). Taken together, these data suggest that FOXO1-mediated expression of G6Pase and PEPCK is critical for gluconeogenesis in the liver during fasting and deregulation of its expression may be involved in the development of diabetes.

FOXO1 has also been proposed to play an important role in development of the pancreas in response to insulin during embryonic development. To investigate the role of FoxO1 in beta cell function, the effect of loss of FoxO1 expression in $I R S 2^{-1-}$ mice was investigated in mice (52). Inactivation of insulin receptor signaling by IRS2 deletion impairs beta cell proliferation and function. FoxO1 haplo-insufficiency restores proliferation in beta cells from $I R S 2^{-7-}$ mice, which correlates with expression of the pancreatic transcription factor Pdx1. This protein plays an important role in the development of the pancreas as well as maintenance of beta cell function. FoxO1 acts as transcriptional repressor of $\mathrm{Pdx} 1$ expression in the pancreas (52), and this suggests that FOXO1 blocks beta cell proliferation and function through repression of $\mathrm{Pdx} 1$ expression.

In addition to having a role in the regulation of glucose metabolism, FOXO1 is also an important regulator of lipid 
metabolism through modulation of apoliprotein (apo)C-III expression levels. apoC-III is an inhibitor of lipoprotein lipase and its synthesis in the liver is blocked by insulin (2). Elevated apoC-III levels have been associated with the development of hypertriglyceridemia in diabetic patients (89). Ectopic expression FOXO1 in rat primary hepatocytes increases apocIII mRNA, which can be blocked by insulin stimulation (2). Infection of mice with an adenovirus expressing FOXO1 increased apoC-III and triglyceride levels in plasma and additionally high Foxo1 expression in diabetic mice correlated with high apoC-III plasma levels (2). Taken together, activation of FOXO1 activity can contribute to the development of diabetes through transcriptional regulation of G6Pase, PEPCK, and apoC-III in the liver and repressing Pdx1 in beta cells, resulting in decreased insulin sensitivity, decreased beta cell numbers, and increased triglyceride levels in the blood.

In addition to the effects on genes involved in metabolism in the liver, pancreas, and adipose tissue, FOXO1 is also involved in hormonal regulation of food intake in the hypothalamus $(49,51)$. The anorexigenic hormone leptin decreases food intake through direct actions in hypothalamus through binding to the leptin receptor and activation of PI3K signaling [reviewed in (85)]. Foxo1 is expressed in the hypothalamus in mice and its expression is decreased upon stimulation with leptin (49). In mice, microinjection of an adenovirus encoding a constitutively active Foxo1 mutant in the hypothalamus inhibited leptin-induced reduction in food intake and decreased body weight, indicating that leptin-mediated inhibition of Foxo1 is required for the anorexigenic actions of this hormone. Previous research has indicated that leptin decreases in food intake by downregulation of the hormones Agouti-related protein (Agrp) and neuropeptide Y (NpY), while enhancing expression of pro-opiomelanocortin (POMC) [reviewed in (85)]. In the hypothalamus, expression of constitutively active Foxo1 inhibited the regulation of these genes by leptin (51). In addition, ectopic expression of Foxo1 directly increased expression of Agrp and NpY, while decreasing POMC expression by direct association with their promoters $(49,51)$. These results demonstrate that Foxo1 is both necessary and sufficient for regulating Agrp, NpY, and POMC expression in response to leptin. The differential effect of Foxo1 on these genes might result from association of distinct coactivator-corepressor complexes to the promoters. While active Foxo1 increased binding of the nuclear coactivator p300 to the Agrp promoter, inhibition of Foxo1 expression resulted in binding of the corepressor nuclear corepressor. In contrast, the POMC promoter showed an opposite pattern, suggesting that the FOXO1-induced recruitment of either repressors or coactivators to the promoter is responsible for the differential effect on Agrp and POMC expression (51).

\section{FOXOs in the Immune System}

It has been proposed that low-grade inflammation of adipose tissue can contribute to insulin resistance in type 2 diabetes (90). Stimulating adipocytes with TNF $\alpha$ blocks insulin-induced phosphorylation of FOXO1, suggesting that pro-inflammatory cytokines can modulate FOXO activity. In addition, FOXO1 activity was found to increase expression of the transcription factor $\mathrm{C} / \mathrm{EBP} \beta$ (43). Knockdown of FOXO1 in adipocytes decreased $\mathrm{C} / \mathrm{EBP} \beta$ expression and reduced expression of the pro-inflammatory cytokines chemokine
(CCL motif) ligand 2 and IL-6. These results suggest that local inflammation might increase FOXO1 activity in adipose tissue, thereby providing a link between inflammation and insulin resistance (43).

FOXO1 transcriptional activity may directly control inflammation since it has recently been shown that FOXO1 can increase production of the inflammatory cytokine IL-1 $\beta$ (94). Ectopic expression of Foxo1 in a macrophage cell line was found to increase the level of IL- $\beta$ and IL-2 production after stimulation with LPS (94). Further, in macrophages isolated from LPS-treated mice, higher Foxo1 and IL-1 $\beta$ mRNA levels were observed, correlating with increased plasma concentrations of IL- $1 \beta$. ChIP analysis confirmed that IL- $1 \beta$ is a direct transcriptional target of Foxo1 and it was shown that activation of $\mathrm{NF} \kappa \mathrm{B}$ could increase Foxo1 binding to the IL- $\beta$ promoter. In macrophages from diabetic mice, expression levels of Foxo1 and IL-1 $\beta$ were increased, suggesting that FOXO1 also regulates IL- $1 \beta$ expression in vivo (94). Taken together, these results suggest that FOXO1 might form a direct link between inflammation and diabetes.

The role of FOXO1 in T cell function has been investigated in mice with T cell-specific deletion of Foxo1 (70). Analysis of T cells isolated from the spleen of these mice revealed that the percentage of activated CD4 and CD8 T cells was increased, whereas the percentage of naive CD4 and CD8 T cells was decreased. Phenotypic analysis of the marker expression profile of Foxo1 deficient $\mathrm{T}$ cells demonstrated a decreased expression of the IL-7 receptor (IL-7R) on mature T cells. IL-7 is required for survival and homeostatic proliferation of peripheral T cells and stimulation of Foxo1-deficient T cells with IL-7 in vitro was insufficient to rescue cells from starvation-induced cell death. IL7-R was found to be a direct transcriptional target of Foxo1. These data suggest that FOXO1 plays an important role in $\mathrm{T}$ cell homeostasis by increasing IL7-R, which is important for the maintenance of naive $\mathrm{T}$ cells (70).

\section{Regulation of Proteolysis and Autophagy}

Both during fasting and in a variety of diseases, including diabetes, cancer, and sepsis, muscle size decreases in a process termed atrophy, a state that is characterized by accelerated proteolysis (108). Proteolysis is caused through increased protein turnover through the ubiquitin-proteosome pathway as well as increased lysosomal proteolysis as a consequence of autophagy (107). Recently, FOXOs have been shown to play an important role in both these processes (Fig. 6).

During starvation of murine muscle cells expression of the muscle-specific ubiquitin ligase atrogin-1 increases, which can be blocked by activation of PKB (83). Further experiments revealed that $\mathrm{FOXO} 3$ can directly regulate expression of atrogin-1. Ectopic expression of an active FOXO3 mutant not only caused increased atrogin-1 expression but also resulted in reduction in muscle fiber size (83). Further Skurk et al. demonstrated that FOXO3 can regulate cell size in cardiac muscle in vivo. Injection of viral vectors expressing FOXO3 directly in the heart of mice increased atrogin-1 expression and reduced the cell size, indicating that in vivo FOXO3 can induce cardiac hypertrophy (91).

Two recent studies have demonstrated that, in addition to proteosomal degradation, FOXO3 can also induce lysosomal degradation through induction of autophagy. Using specific inhibitors for either proteosomal or lysosomal proteolysis, it 


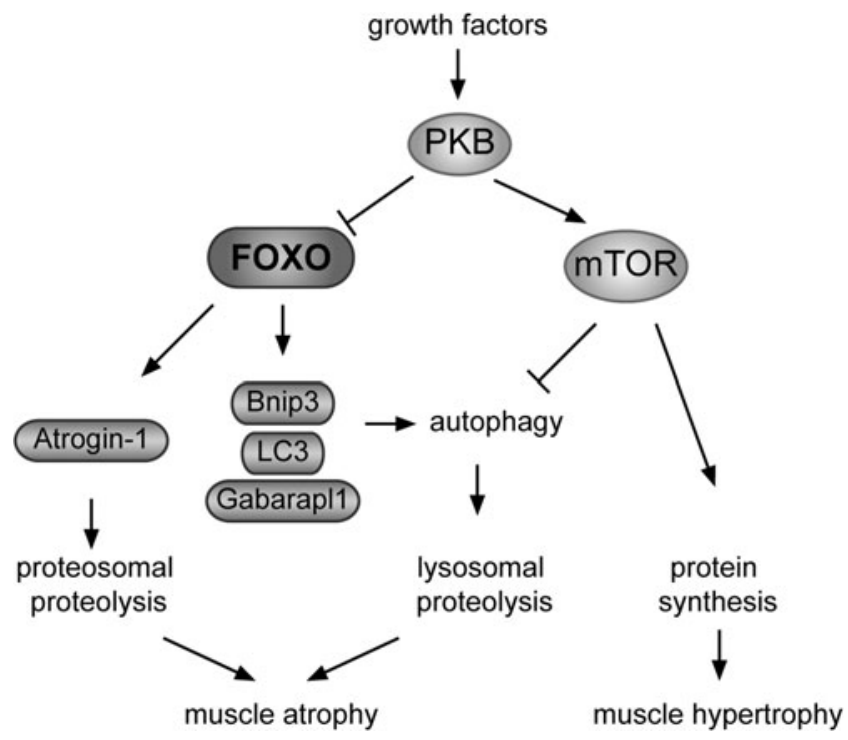

FIG. 6. Role of FOXOs in muscle atrophy. FOXOs can induce atrophy in muscle cells by stimulating both lysosomal and proteosomal protein breakdown. Upregulation of Bnip3, LC3, and Gabarapl1 is associated with FOXO-induced autophagy and increased lysosomal proteolysis, whereas the upregulation of the ubiquitin ligase atrogin3 increases proteolysis via the proteosome. See Regulation of Proteolysis and Autophagy for further explanation. Bnip3, $\mathrm{Bcl} /$ adenovirus E1B $19 \mathrm{kDa}$ protein-interacting protein 3; Gabarapl1, GABA(A) receptor-associated protein like 1.

was shown that in muscle cells both pathways contribute to FOXO3-induced protein degradation (107). Further, it was shown that ectopic expression of an active FOXO3 mutant in adult muscle fibers from mice induced the formation of autophagosomes, resulting in an increase in lysosomal proteolysis. In contrast, knockdown of Foxo3 in these muscles fibers blocked autophagosome formation after starvation, demonstrating that FOXO3 activity is both required and sufficient for induction of autophagy in muscle cells. Microarray and ChIP analysis revealed the upregulation of a number of mRNA transcripts involved in protein breakdown, including proteins involved in degradation through the proteosome including atrogin- 1 and autophagy-related genes including GABA(A) receptor-associated protein like 1 (Gabarapl1), atg121, and Beclin1 (107). However, it is unclear whether upregulation of these autophagy-related genes directly drives autophagic flux or whether they are upregulated to replace the components that are consumed during this process. A second report by Mammucari et al. demonstrated that in skeletal muscle mRNA levels of multiple proteins involved in protein degradation increased after fasting, including LC3, Gabarapl1, Bcl/adenovirus E1B $19 \mathrm{kDa}$ protein-interacting protein 3 (Bnip3), and atrogin1 (57). Further, analysis of LC3 expression by fluorescent microscopy revealed the formation of autophagosomes in muscles from fasted animals and these effects could be blocked by knockdown of Foxo3 expression. Expression of a constitutively active FOXO3 mutant in muscles was sufficient to induce autophagosomes in vivo, which was in turn dependent on transcriptional upregulation of Bnip3, a Bcl-2-related protein that is involved in regulation of autophagy. Bnip3 overexpression was also sufficient to induce autophagosomes, indicating that in vivo FOXO3 controls autophagy through regulation of Bnip3 expression (57). However, these results are in contrast to a report by Zhao et al. in which no upregulation of Bnip3 expression was observed after $\mathrm{FOXO} 3$ activation in vitro (107). How FOXO3 induces autophagy in the absence of Bnip3 expression remains unclear and awaits further research.

Besides regulation of atrophy in skeletal muscle, FOXOs have also been shown to play a role in autophagy in cardiomyocytes during fasting (87). Ectopic expression of a dominant negative FOXO1 mutant blocked the starvation-induced reduction in cell size of cultured cardiomyocytes. In contrast, ectopic expression of FOXO1 or FOXO3 increased autophagosome formation, reduced cell size, and induced expression of the autophagy-related genes LC3, Gabarapl1, and Atg12 (87). These results suggest that FOXOs can directly regulate cardiomyocyte cell size through modulation of autophagy.

Besides regulating atrophy by upregulating targets involved in protein degradation, FOXOs have also been described to induce atrophy in skeletal muscle by upregulation of myostatin, a secreted factor that potently induces atrophy by inhibiting protein synthesis (1). Activation of FOXO1 in myoblasts increased myostatin mRNA and increased activity of a myostatin promoter reporter (1). However, the importance of the upregulation of myostatin expression in FOXOinduced atrophy remains unclear.

Taken together, FOXO3 is an important regulator of muscle atrophy by regulating both proteosomal as well as lysomal proteolysis resulting in decreased muscle function.

\section{FOXO Proteins as Tumor Suppressors}

FOXOs regulate many target genes involved in cell cycle arrest and apoptosis, suggesting that FOXO proteins might act as true tumor suppressors. This is indirectly supported by the finding that the PI3K-PKB pathway is frequently overactivated in cancer, resulting in FOXO inactivation (25). In a number of studies it has been shown that reactivation of FOXOs either by ectopic expression or by inhibition of PI3K in a variety of cancer cells resulted in induction of apoptosis. FOXO3-mediated upregulation of the pro-apoptotic Bcl-2 family member Bim has been shown to induce apoptosis in breast cancer cells, chronic leukemia cells, and gastric cancer cells $(26,96,104)$. Further, treatment of glioma cells with the chemotherapeutic drug cyclosporin A induced apoptosis through FOXO1-mediated induction of FasL expression (19). These results suggest that the inactivation of FOXOs plays an important role in maintaining sustained survival of tumor cells. The development of a inducible Foxo1 ${ }^{-1-}$, Foxo3 ${ }^{-/-}$, and Foxo4 ${ }^{-/-}$mouse model demonstrated the importance of FOXOs in oncogenesis (72). After conditional deletion of Foxo1, Foxo3, and Foxo4, mice developed lymphoblastic thymic lymphomas and hemangiomas. Disruption of only two Foxo genes resulted in a more moderate phenotype, demonstrating that FOXOs are functional redundant tumor suppressors (72).

Further, FOXO3 can influence the transcription of a large subset of target genes by inhibiting the proto-oncogene c-myc (22). Myc is a positive regulator of proliferation and survival and found to be upregulated in a variety of cancers. In a colon carcinoma cell line microarrray analysis after FOXO3 activation identified Mxi1, a transcriptional inhibitor of c-myc, as a putative FOXO3 target (22). Comparative analysis of FOXO3regulated transcripts with a database of c-myc target genes 
revealed an overlapping set of transcripts with FOXO3downregulated genes, suggesting that FOXO3 could directly inhibit c-myc signaling. Knockdown of Mxi1 expression increased expression of the FOXO3-repressed c-myc targets, suggesting that the induction of Mxi expression contributes to the FOXO3-induced downregulation of c-myc. In addition, knockdown of Mxi1 reduced the block in cell cycle progression after FOXO3 activation, indicating that Mxi1 contributes to inhibition of proliferation by FOXO3 (22).

In some cell types FOXO transcriptional activity not only prevents cells from proliferating but also actively induces a differentiation program. Chromic myeloid leukemia (CML) is characterized by expression of the oncogenic fusion protein $\mathrm{Bcr}-\mathrm{Abl}$, which results in constitutive activation of multiple signaling pathways, including the PI3K-PKB pathway (45). Inhibition of the kinase activity of Bcr-Abl with the specific inhibitor imatinib induced activation of $\mathrm{FOXO} 3$ in the CML celline K562 and, utilizing microarray analysis, the helix-loophelix protein Id1 was identified as a novel FOXO target (10). Inhibition of Bcr-Abl or overexpression of active FOXO3 induced differentiation of CML cells toward erythrocytes, which was blocked by Id1-specific knockdown (10). This suggests that Bcr-Abl maintains the leukemic phenotype by repressing FOXO3-induced differentiation.

Besides the tumor-suppressor function of FOXOs, it has also been suggested that FOXOs can actually contribute to enhanced survival of drug-resistant oncogenic cells. It was observed that in doxyrubicin-resistant K562 CML cells, the levels of dephosphorylated FOXO3 are increased compared to the parental cell line, whereas phosphorylation and activity of PKB was also increased (42). Further, activation of FOXO3 in K562 cells increased PKB phosphorylation, suggesting that FOXO3 acts in a positive feedback loop to activate PKB. Activation of FOXO3 resulted in transcriptional upregulation of one of the catalytic subunits of PI3K; p $110 \alpha$, suggesting that the FOXO3-induced activation of PKB was mediated by increasing PI3K activity. However, knockdown of $\mathrm{p} 110 \alpha$ did not decrease FOXO3-induced phosphorylation of PKB, indicating that other mechanisms play a role in this feedback loop (42).

\section{Conclusions}

Through regulation of multiple transcriptional targets FOXOs modulate a plethora of cellular functions, including proliferation, apoptosis, stress resistance, and metabolism. Since many of these cellular responses are deregulated in cancer, FOXOs are important regulators of tissue homeostasis. The outcome of FOXO activation depends largely on the cellular context. This has recently been specifically highlighted by fact that comparative analysis of FOXO-regulated transcripts in NSCs, HSCs, and lymphomas from the Foxo triple knockout mice demonstrated very little overlap, indicating that FOXOs regulate their transcriptional targets in a highly cell typespecific manner. FOXOs associate with a large variety of cofactors that influence their transcriptional program and detailed knowledge about the specific interactions in different cell types might provide clues on the cell type specific consequences of FOXO activation [reviewed in (103)]. In addition, although the different FOXOs isoforms show an overlapping expression pattern, deletion of the individual FOXO genes in mice gives distinct phenotypes, indicating nonredundant roles for FOXOs in vivo. The future identification of differential regulated transcriptional targets will give more insights in the complex biology of FOXO-mediated transcription.

\section{References}

1. Allen DL and Unterman TG. Regulation of myostatin expression and myoblast differentiation by FoxO and SMAD transcription factors. Am J Physiol Cell Physiol 292: C188C199, 2007.

2. Altomonte J, Cong L, Harbaran S, Richter A, Xu J, Meseck M, and Dong HH. Foxo1 mediates insulin action on apoC-III and triglyceride metabolism. J Clin Invest 114: 1493-1503, 2004.

3. Altomonte J, Richter A, Harbaran S, Suriawinata J, Nakae J, Thung SN, Meseck M, Accili D, and Dong H. Inhibition of Foxo1 function is associated with improved fasting glycemia in diabetic mice. Am J Physiol Endocrinol Metab 285: E718-E728, 2003.

4. Anderson MJ, Viars CS, Czekay S, Cavenee WK, and Arden KC. Cloning and characterization of three human forkhead genes that comprise an FKHR-like gene subfamily. Genomics 47: 187-199, 1998.

5. Bakker WJ, Blazquez-Domingo M, Kolbus A, Besooyen J, Steinlein P, Beug H, Coffer PJ, Lowenberg B, von LM, and van Dijk TB. FoxO3a regulates erythroid differentiation and induces BTG1, an activator of protein arginine methyl transferase 1. J Cell Biol 164: 175-184, 2004.

6. Bakker WJ, Harris IS, and Mak TW. FOXO3a is activated in response to hypoxic stress and inhibits HIF1-induced apoptosis via regulation of CITED2. Mol Cell 28: 941-953, 2007.

7. Barthel A and Schmoll D. Novel concepts in insulin regulation of hepatic gluconeogenesis. Am J Physiol Endocrinol Metab 285: E685-E692, 2003.

8. Besson A, Dowdy SF, and Roberts JM. CDK inhibitors: cell cycle regulators and beyond. Dev Cell 14: 159-169, 2008.

9. Biggs WH, Cavenee WK, and Arden KC. Identification and characterization of members of the FKHR (FOX O) subclass of winged-helix transcription factors in the mouse. Mamm Genome 12: 416-425, 2001.

10. Birkenkamp KU, Essafi A, van der Vos KE, da Costa M, Hui RC, Holstege F, Koenderman L, Lam EW and Coffer PJ. FOXO3a induces differentiation of Bcr-Abl-transformed cells through transcriptional down-regulation of Id1. J Biol Chem 282: 2211-2220, 2007.

11. Boura E, Silhan J, Herman P, Vecer J, Sulc M, Teisinger J, Obsilova V, and Obsil T. Both the N-terminal loop and wing W2 of the forkhead domain of transcription factor Foxo4 are important for DNA binding. J Biol Chem 282: 8265-8275, 2007.

12. Brunelle JK and Letai A. Control of mitochondrial apoptosis by the Bcl-2 family. J Cell Sci 122: 437-441, 2009.

13. Brunet A, Bonni A, Zigmond MJ, Lin MZ, Juo P, Hu LS, Anderson MJ, Arden KC, Blenis J, and Greenberg ME. Akt promotes cell survival by phosphorylating and inhibiting a Forkhead transcription factor. Cell 96: 857-868, 1999.

14. Brunet A, Park J, Tran H, Hu LS, Hemmings BA, and Greenberg ME. Protein kinase SGK mediates survival signals by phosphorylating the forkhead transcription factor FKHRL1 (FOXO3a). Mol Cell Biol 21: 952-965, 2001.

15. Bueler H. Impaired mitochondrial dynamics and function in the pathogenesis of Parkinson's disease. Exp Neurol 218: 235-246, 2009.

16. Castrillon DH, Miao L, Kollipara R, Horner JW, and DePinho RA. Suppression of ovarian follicle activation in mice by the transcription factor Foxo3a. Science 301: 215-218, 2003. 
17. Chen J, Yusuf I, Andersen HM, and Fruman DA. FOXO transcription factors cooperate with delta EF1 to activate growth suppressive genes in B lymphocytes. J Immunol 176: 2711-2721, 2006.

18. Chiribau CB, Cheng L, Cucoranu IC, Yu YS, Clempus RE, and Sorescu D. FOXO3A regulates peroxiredoxin III expression in human cardiac fibroblasts. J Biol Chem 283: 8211-8217, 2008.

19. Ciechomska I, Pyrzynska B, Kazmierczak P, and Kaminska B. Inhibition of Akt kinase signalling and activation of Forkhead are indispensable for upregulation of FasL expression in apoptosis of glioma cells. Oncogene 22: 7617-7627, 2003.

20. Daitoku H, Yamagata K, Matsuzaki H, Hatta M, and Fukamizu A. Regulation of PGC-1 promoter activity by protein kinase B and the forkhead transcription factor FKHR. Diabetes 52: 642-649, 2003.

21. Dansen TB, Kops GJ, Denis S, Jelluma N, Wanders RJ, Bos JL, Burgering BM, and Wirtz KW. Regulation of sterol carrier protein gene expression by the forkhead transcription factor FOXO3a. J Lipid Res 45: 81-88, 2004.

22. Delpuech O, Griffiths B, East P, Essafi A, Lam EW, Burgering B, Downward J, and Schulze A. Induction of Mxi1-SR alpha by FOXO3a contributes to repression of Myc-dependent gene expression. Mol Cell Biol 27: 49174930, 2007.

23. Dijkers PF, Medema RH, Lammers JW, Koenderman L, and Coffer PJ. Expression of the pro-apoptotic Bcl-2 family member Bim is regulated by the forkhead transcription factor FKHR-L1. Curr Biol 10: 1201-1204, 2000.

24. Dijkers PF, Medema RH, Pals C, Banerji L, Thomas NS, Lam EW, Burgering BM, Raaijmakers JA, Lammers JW, Koenderman L, and Coffer PJ. Forkhead transcription factor FKHR-L1 modulates cytokine-dependent transcriptional regulation of p27(KIP1). Mol Cell Biol 20: 9138-9148, 2000.

25. Engelman JA. Targeting PI3K signalling in cancer: opportunities, challenges and limitations. Nat Rev Cancer 9: 550-562, 2009.

26. Essafi A, Fernandez de MS, Hassen YA, Soeiro I, Mufti GJ, Thomas NS, Medema RH, and Lam EW. Direct transcriptional regulation of Bim by FoxO3a mediates STI571induced apoptosis in Bcr-Abl-expressing cells. Oncogene 24: 2317-2329, 2005.

27. Essaghir A, Dif N, Marbehant CY, Coffer PJ, and Demoulin JB. The transcription of FOXO genes is stimulated by FOXO3 and repressed by growth factors. J Biol Chem 284: 10334-10342, 2009.

28. Fernandez de MS, Essafi A, Soeiro I, Pietersen AM, Birkenkamp KU, Edwards CS, Martino A, Nelson BH, Francis JM, Jones MC, Brosens JJ, Coffer PJ, and Lam EW. FoxO3a and BCR-ABL regulate cyclin D2 transcription through a STAT5/BCL6-dependent mechanism. Mol Cell Biol 24: 10058-10071, 2004.

29. Finkel T, Serrano M, and Blasco MA. The common biology of cancer and ageing. Nature 448: 767-774, 2007.

30. Furukawa-Hibi Y, Yoshida-Araki K, Ohta T, Ikeda K, and Motoyama N. FOXO forkhead transcription factors induce G(2)-M checkpoint in response to oxidative stress. J Biol Chem 277: 26729-26732, 2002.

31. Furuyama T, Kitayama K, Yamashita H, and Mori N. Forkhead transcription factor FOXO1 (FKHR)-dependent induction of PDK4 gene expression in skeletal muscle during energy deprivation. Biochem J 375: 365-371, 2003.

32. Furuyama T, Nakazawa T, Nakano I, and Mori N. Identification of the differential distribution patterns of mRNAs and consensus binding sequences for mouse DAF-16 homologues. Biochem J 349: 629-634, 2000.

33. Gilley J, Coffer PJ, and Ham J. FOXO transcription factors directly activate bim gene expression and promote apoptosis in sympathetic neurons. J Cell Biol 162: 613-622, 2003.

34. Guicciardi ME and Gores GJ. Life and death by death receptors. FASEB J 23: 1625-1637, 2009.

35. Guo $S$ and Sonenshein GE. Forkhead box transcription factor FOXO3a regulates estrogen receptor alpha expression and is repressed by the Her-2/neu/phosphatidylinositol 3kinase/Akt signaling pathway. Mol Cell Biol 24: 8681-8690, 2004.

36. Han CY, Cho KB, Choi HS, Han HK, and Kang KW. Role of FoxO1 activation in MDR1 expression in adriamycinresistant breast cancer cells. Carcinogenesis 29: 1837-1844, 2008.

37. Hideshima T, Nakamura N, Chauhan D, and Anderson KC. Biologic sequelae of interleukin-6 induced PI3-K/Akt signaling in multiple myeloma. Oncogene 20: 5991-6000, 2001.

38. Ho KK, Myatt SS, and Lam EW. Many forks in the path: cycling with FoxO. Oncogene 27: 2300-2311, 2008.

39. Hosaka T, Biggs WH, III, Tieu D, Boyer AD, Varki NM, Cavenee WK, and Arden KC. Disruption of forkhead transcription factor (FOXO) family members in mice reveals their functional diversification. Proc Natl Acad Sci USA 101: 2975-2980, 2004.

40. Hu MC, Lee DF, Xia W, Golfman LS, Ou-Yang F, Yang JY, Zou Y, Bao S, Hanada N, Saso H, Kobayashi R, and Hung MC. IkappaB kinase promotes tumorigenesis through inhibition of forkhead FOXO3a. Cell 117: 225-237, 2004.

41. Huang H, Regan KM, Lou Z, Chen J, and Tindall DJ. CDK2dependent phosphorylation of FOXO1 as an apoptotic response to DNA damage. Science 314: 294-297, 2006.

42. Hui RC, Gomes AR, Constantinidou D, Costa JR, Karadedou CT, Fernandez de MS, Wymann MP, Brosens JJ, Schulze A, and Lam EW. The forkhead transcription factor FOXO3a increases phosphoinositide-3 kinase/ Akt activity in drug-resistant leukemic cells through induction of PIK3CA expression. Mol Cell Biol 28: 5886-5898, 2008.

43. Ito Y, Daitoku H, and Fukamizu A. Foxo1 increases proinflammatory gene expression by inducing C/EBPbeta in TNF-alpha-treated adipocytes. Biochem Biophys Res Commun 378: 290-295, 2009.

44. Jacobs FM, van der Heide LP, Wijchers PJ, Burbach JP, Hoekman MF, and Smidt MP. FoxO6, a novel member of the FoxO class of transcription factors with distinct shuttling dynamics. J Biol Chem 278: 35959-35967, 2003.

45. Jagani Z, Singh A, and Khosravi-Far R. FoxO tumor suppressors and BCR-ABL-induced leukemia: a matter of evasion of apoptosis. Biochim Biophys Acta 1785: 63-84, 2008.

46. Jonsson $\mathrm{H}$, Allen $\mathrm{P}$, and Peng SL. Inflammatory arthritis requires Foxo3a to prevent Fas ligand-induced neutrophil apoptosis. Nat Med 11: 666-671, 2005.

47. Katayama K, Nakamura A, Sugimoto Y, Tsuruo T and Fujita N. FOXO transcription factor-dependent p15(INK4b) and p19(INK4d) expression. Oncogene 27: 1677-1686, 2008.

48. Kenyon C, Chang J, Gensch E, Rudner A and Tabtiang R. A C. elegans mutant that lives twice as long as wild type. Nature 366: 461-464, 1993.

49. Kim MS, Pak YK, Jang PG, Namkoong C, Choi YS, Won JC, Kim KS, Kim SW, Kim HS, Park JY, Kim YB, and Lee KU. Role of hypothalamic Foxo1 in the regulation of food intake and energy homeostasis. Nat Neurosci 9: 901-906, 2006. 
50. Kimura KD, Tissenbaum HA, Liu Y, and Ruvkun G. daf-2, an insulin receptor-like gene that regulates longevity and diapause in Caenorhabditis elegans. Science 277: 942-946, 1997.

51. Kitamura T, Feng Y, Kitamura YI, Chua SC Jr., Xu AW, Barsh GS, Rossetti L, and Accili D. Forkhead protein FoxO1 mediates Agrp-dependent effects of leptin on food intake. Nat Med 12: 534-540, 2006.

52. Kitamura T, Nakae J, Kitamura Y, Kido Y, Biggs WH, III, Wright CV, White MF, Arden KC, and Accili D. The forkhead transcription factor Foxo1 links insulin signaling to Pdx1 regulation of pancreatic beta cell growth. J Clin Invest 110: 1839-1847, 2002.

53. Kops GJ, Dansen TB, Polderman PE, Saarloos I, Wirtz KW, Coffer PJ, Huang TT, Bos JL, Medema RH, and Burgering $\mathrm{BM}$. Forkhead transcription factor FOXO3a protects quiescent cells from oxidative stress. Nature 419: 316-321, 2002.

54. Kops GJ, Medema RH, Glassford J, Essers MA, Dijkers PF, Coffer PJ, Lam EW, and Burgering BM. Control of cell cycle exit and entry by protein kinase B-regulated forkhead transcription factors. Mol Cell Biol 22: 2025-2036, 2002.

55. Li H, Liang J, Castrillon DH, DePinho RA, Olson EN, and Liu ZP. FoxO4 regulates tumor necrosis factor alpha-directed smooth muscle cell migration by activating matrix metalloproteinase 9 gene transcription. Mol Cell Biol 27: 2676-2686, 2007.

56. Lin L, Hron JD, and Peng SL. Regulation of NF-kappaB, Th activation, and autoinflammation by the forkhead transcription factor Foxo3a. Immunity 21: 203-213, 2004.

57. Mammucari C, Milan G, Romanello V, Masiero E, Rudolf R, Del PP, Burden SJ, Di LR, Sandri C, Zhao J, Goldberg $\mathrm{AL}$, Schiaffino S, and Sandri M. FoxO3 controls autophagy in skeletal muscle in vivo. Cell Metab 6: 458-471, 2007.

58. Martinez-Gac L, Marques M, Garcia Z, Campanero MR, and Carrera AC. Control of cyclin G2 mRNA expression by forkhead transcription factors: novel mechanism for cell cycle control by phosphoinositide 3-kinase and forkhead. Mol Cell Biol 24: 2181-2189, 2004.

59. Matsumoto M, Han S, Kitamura T, and Accili D. Dual role of transcription factor FoxO1 in controlling hepatic insulin sensitivity and lipid metabolism. J Clin Invest 116: 2464 2472, 2006.

60. Mawal-Dewan M, Lorenzini A, Frisoni L, Zhang H, Cristofalo VJ, and Sell C. Regulation of collagenase expression during replicative senescence in human fibroblasts by Aktforkhead signaling. J Biol Chem 277: 7857-7864, 2002.

61. Medema RH, Kops GJ, Bos JL, and Burgering BM. AFX-like Forkhead transcription factors mediate cell-cycle regulation by Ras and PKB through p27kip1. Nature 404: 782-787, 2000.

62. Mei Y, Zhang Y, Yamamoto K, Xie W, Mak TW, and You H. FOXO3a-dependent regulation of Pink1 (Park6) mediates survival signaling in response to cytokine deprivation. Proc Natl Acad Sci USA 106: 5153-5158, 2009.

63. Modur V, Nagarajan R, Evers BM, and Milbrandt J. FOXO proteins regulate tumor necrosis factor-related apoptosis inducing ligand expression. Implications for PTEN mutation in prostate cancer. J Biol Chem 277: 47928-47937, 2002.

64. Nakae J, Biggs WH III, Kitamura T, Cavenee WK, Wright $\mathrm{CV}$, Arden $\mathrm{KC}$, and Accili D. Regulation of insulin action and pancreatic beta-cell function by mutated alleles of the gene encoding forkhead transcription factor Foxo1. Nat Genet 32: 245-253, 2002.

65. Nakae J, Kitamura T, Kitamura Y, Biggs WH III, Arden KC, and Accili D. The forkhead transcription factor Foxo1 regulates adipocyte differentiation. Dev Cell 4: 119-129, 2003.
66. Nemoto $\mathrm{S}$ and Finkel T. Redox regulation of forkhead proteins through a p66shc-dependent signaling pathway. Science 295: 2450-2452, 2002.

67. Ni YG, Wang N, Cao DJ, Sachan N, Morris DJ, Gerard RD, Kuro O, Rothermel BA, and Hill JA. FoxO transcription factors activate Akt and attenuate insulin signaling in heart by inhibiting protein phosphatases. Proc Natl Acad Sci USA 104: 20517-20522, 2007.

68. Obsil T and Obsilova V. Structure/function relationships underlying regulation of FOXO transcription factors. Oncogene 27: 2263-2275, 2008.

69. Onuma H, Vander Kooi BT, Boustead JN, Oeser JK, and O'Brien RM. Correlation between FOXO1a (FKHR) and FOXO3a (FKHRL1) binding and the inhibition of basal glucose-6-phosphatase catalytic subunit gene transcription by insulin. Mol Endocrinol 20: 2831-2847, 2006.

70. Ouyang W, Beckett O, Flavell RA, and Li MO. An essential role of the Forkhead-box transcription factor Foxo1 in control of $\mathrm{T}$ cell homeostasis and tolerance. Immunity 30: 358-371, 2009.

71. Paik JH, Ding Z, Narurkar R, Ramkissoon S, Muller F, Kamoun WS, Chae SS, Zheng H, Ying H, Mahoney J, Hiller D, Jiang S, Protopopov A, Wong WH, Chin L, Ligon KL, and DePinho RA. FoxOs cooperatively regulate diverse pathways governing neural stem cell homeostasis. Cell Stem Cell 5: 540-553, 2009.

72. Paik JH, Kollipara R, Chu G, Ji H, Xiao Y, Ding Z, Miao L, Tothova Z, Horner JW, Carrasco DR, Jiang S, Gilliland DG, Chin L, Wong WH, Castrillon DH, and DePinho RA. FoxOs are lineage-restricted redundant tumor suppressors and regulate endothelial cell homeostasis. Cell 128: 309-323, 2007.

73. Paolisso G, Galzerano D, Gambardella A, Varricchio G, Saccomanno F, D'Amore A, Varricchio M, and D'Onofrio F. Left ventricular hypertrophy is associated with a stronger impairment of non-oxidative glucose metabolism in hypertensive patients. Eur J Clin Invest 25: 529-533, 1995.

74. Partridge L and Bruning JC. Forkhead transcription factors and ageing. Oncogene 27: 2351-2363, 2008.

75. Potente M, Urbich C, Sasaki K, Hofmann WK, Heeschen C, Aicher A, Kollipara R, DePinho RA, Zeiher AM, and Dimmeler S. Involvement of Foxo transcription factors in angiogenesis and postnatal neovascularization. J Clin Invest 115: 2382-2392, 2005.

76. Puig O, Marr MT, Ruhf ML, and Tjian R. Control of cell number by Drosophila FOXO: downstream and feedback regulation of the insulin receptor pathway. Genes Dev 17: 2006-2020, 2003.

77. Puig $\mathrm{O}$ and Tjian R. Transcriptional feedback control of insulin receptor by dFOXO/FOXO1. Genes Dev 19: 24352446, 2005.

78. Puigserver P, Rhee J, Donovan J, Walkey CJ, Yoon JC, Oriente F, Kitamura Y, Altomonte J, Dong H, Accili D, and Spiegelman BM. Insulin-regulated hepatic gluconeogenesis through FOXO1-PGC-1alpha interaction. Nature 423: 550555, 2003.

79. Qiao L and Shao J. SIRT1 regulates adiponectin gene expression through Foxo1-C/enhancer-binding protein alpha transcriptional complex. J Biol Chem 281: 39915-39924, 2006.

80. Renault VM, Rafalski VA, Morgan AA, Salih DA, Brett JO, Webb AE, Villeda SA, Thekkat PU, Guillerey C, Denko NC, Palmer TD, Butte AJ, and Brunet A. FoxO3 regulates neural stem cell homeostasis. Cell Stem Cell 5: 527-539, 2009.

81. Rokudai S, Fujita N, Kitahara O, Nakamura Y, and Tsuruo T. Involvement of FKHR-dependent TRADD expression in 
chemotherapeutic drug-induced apoptosis. Mol Cell Biol 22: 8695-8708, 2002.

82. Roy UK, Henkhaus RS, Ignatenko NA, Mora J, Fultz KE, and Gerner EW. Wild-type APC regulates caveolin-1 expression in human colon adenocarcinoma cell lines via FOXO1a and C-myc. Mol Carcinog 47: 947-955, 2008.

83. Sandri M, Sandri C, Gilbert A, Skurk C, Calabria E, Picard A, Walsh K, Schiaffino S, Lecker SH, and Goldberg AL. Foxo transcription factors induce the atrophy-related ubiquitin ligase atrogin-1 and cause skeletal muscle atrophy. Cell 117: 399-412, 2004.

84. Schmidt M, Fernandez de Mattos S, van der HA, Klompmaker R, Kops GJ, Lam EW, Burgering BM, and Medema RH. Cell cycle inhibition by FoxO forkhead transcription factors involves downregulation of cyclin D. Mol Cell Biol 22: 7842-7852, 2002.

85. Schwartz MW and Porte D Jr. Diabetes, obesity, and the brain. Science 307: 375-379, 2005.

86. Sekine K, Chen YR, Kojima N, Ogata K, Fukamizu A, and Miyajima A. Foxo1 links insulin signaling to C/EBPalpha and regulates gluconeogenesis during liver development. EMBO J 26: 3607-3615, 2007.

87. Sengupta A, Molkentin JD, and Yutzey KE. FoxO transcription factors promote autophagy in cardiomyocytes. J Biol Chem 284: 28319-28331, 2009.

88. Seoane J, Le HV, Shen L, Anderson SA, and Massague J. Integration of Smad and forkhead pathways in the control of neuroepithelial and glioblastoma cell proliferation. Cell 117: 211-223, 2004.

89. Shachter NS. Apolipoproteins C-I and C-III as important modulators of lipoprotein metabolism. Curr Opin Lipidol 12: 297-304, 2001.

90. Shoelson SE, Lee J, and Goldfine AB. Inflammation and insulin resistance. J Clin Invest 116: 1793-1801, 2006.

91. Skurk C, Izumiya Y, Maatz H, Razeghi P, Shiojima I, Sandri M, Sato K, Zeng L, Schiekofer S, Pimentel D, Lecker S, Taegtmeyer H, Goldberg AL, and Walsh K. The FOXO3a transcription factor regulates cardiac myocyte size downstream of AKT signaling. J Biol Chem 280: 20814-20823, 2005.

92. Stahl M, Dijkers PF, Kops GJ, Lens SM, Coffer PJ, Burgering $\mathrm{BM}$, and Medema RH. The forkhead transcription factor FoxO regulates transcription of p27Kip1 and Bim in response to IL-2. J Immunol 168: 5024-5031, 2002.

93. Stone JR and Yang S. Hydrogen peroxide: a signaling messenger. Antioxid Redox Signal 8: 243-270, 2006.

94. Su D, Coudriet GM, Kim DH, Lu Y, Perdomo G, Qu S, Slusher S, Tse HM, Piganelli J, Giannoukakis N, Zhang J, and Dong $\mathrm{HH}$. FoxO1 links insulin resistance to proinflammatory cytokine IL-1beta production in macrophages. Diabetes 58: 2624-2633, 2009.

95. Sun A, Bagella L, Tutton S, Romano G, and Giordano A. From G0 to $S$ phase: a view of the roles played by the retinoblastoma $(\mathrm{Rb})$ family members in the $\mathrm{Rb}-\mathrm{E} 2 \mathrm{~F}$ pathway. J Cell Biochem 102: 1400-1404, 2007.

96. Sunters A, Fernandez de MS, Stahl M, Brosens JJ, Zoumpoulidou G, Saunders CA, Coffer PJ, Medema RH, Coombes RC, and Lam EW. FoxO3a transcriptional regulation of Bim controls apoptosis in paclitaxel-treated breast cancer cell lines. J Biol Chem 278: 49795-49805, 2003.

97. Tan WQ, Wang K, Lv DY, and Li PF. Foxo3a inhibits cardiomyocyte hypertrophy through transactivating catalase. $J$ Biol Chem 283: 29730-29739, 2008.
98. Tang TT, Dowbenko D, Jackson A, Toney L, Lewin DA, Dent AL, and Lasky LA. The forkhead transcription factor AFX activates apoptosis by induction of the BCL- 6 transcriptional repressor. J Biol Chem 277: 14255-14265, 2002.

99. Tothova Z, Kollipara R, Huntly BJ, Lee BH, Castrillon DH, Cullen DE, McDowell EP, Lazo-Kallanian S, Williams IR, Sears C, Armstrong SA, Passegue E, DePinho RA, and Gilliland DG. FoxOs are critical mediators of hematopoietic stem cell resistance to physiologic oxidative stress. Cell 128: 325-339, 2007.

100. Tran H, Brunet A, Grenier JM, Datta SR, Fornace AJ Jr., DiStefano PS, Chiang LW, and Greenberg ME. DNA repair pathway stimulated by the forkhead transcription factor FOXO3a through the Gadd45 protein. Science 296: 530-534, 2002.

101. Valente EM, bou-Sleiman PM, Caputo V, Muqit MM, Harvey K, Gispert S, Ali Z, Del TD, Bentivoglio AR, Healy DG, Albanese A, Nussbaum R, Gonzalez-Maldonado R, Deller T, Salvi S, Cortelli P, Gilks WP, Latchman DS, Harvey RJ, Dallapiccola B, Auburger G, and Wood NW. Hereditary early-onset Parkinson's disease caused by mutations in PINK1. Science 304: 1158-1160, 2004.

102. van den Heuvel AP, Schulze A, and Burgering BM. Direct control of caveolin-1 expression by FOXO transcription factors. Biochem J 385: 795-802, 2005.

103. van der Vos and Coffer PJ. FOXO-binding partners: it takes two to tango. Oncogene 27: 2289-2299, 2008.

104. Yamamura $Y$, Lee WL, Inoue $K$, Ida $H$, and Ito Y. RUNX3 cooperates with FoxO3a to induce apoptosis in gastric cancer cells. J Biol Chem 281: 5267-5276, 2006.

105. You H, Pellegrini M, Tsuchihara K, Yamamoto K, Hacker G, Erlacher M, Villunger A, and Mak TW. FOXO3a-dependent regulation of Puma in response to cytokine/growth factor withdrawal. J Exp Med 203: 1657-1663, 2006.

106. Yuan Z, Becker EB, Merlo P, Yamada T, DiBacco S, Konishi $Y$, Schaefer EM, and Bonni A. Activation of FOXO1 by Cdk1 in cycling cells and postmitotic neurons. Science 319: 1665-1668, 2008.

107. Zhao J, Brault JJ, Schild A, Cao P, Sandri M, Schiaffino S, Lecker SH, and Goldberg AL. FoxO3 coordinately activates protein degradation by the autophagic/lysosomal and proteasomal pathways in atrophying muscle cells. Cell Metab 6: 472-483, 2007.

108. Zhao J, Brault JJ, Schild A, and Goldberg AL. Coordinate activation of autophagy and the proteasome pathway by FoxO transcription factor. Autophagy 4: 378-380, 2008.

Address correspondence to: Prof. Paul J. Coffer Molecular Immunology Lab Department of Immunology University Medical Center Utrecht Lundlaan 6, 3584 EA Utrecht

The Netherlands

E-mail: p.j.coffer@umcutrecht.nl

Date of first submission to ARS Central, June 23, 2010; date of final revised submission, July 25, 2010; date of acceptance, August 1, 2010. 


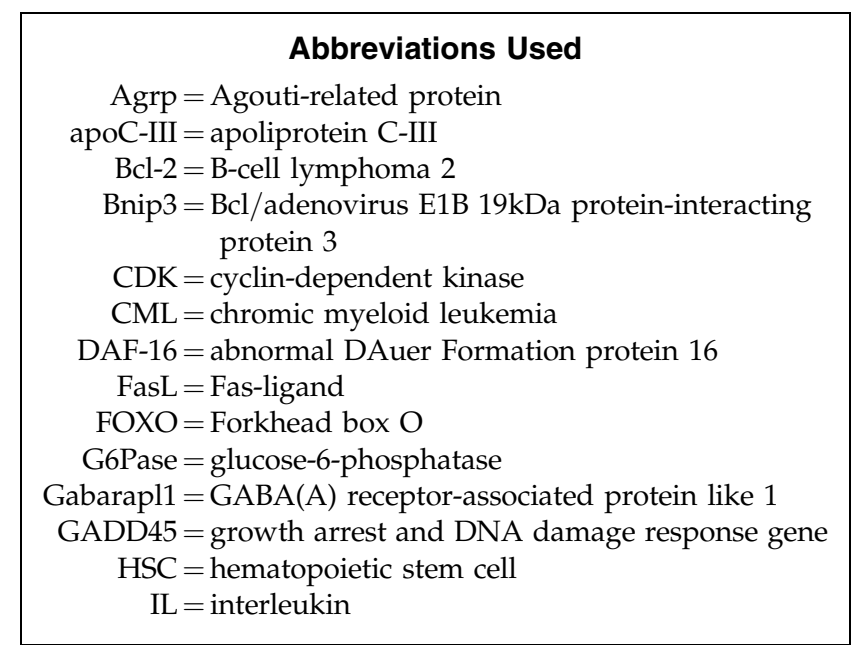

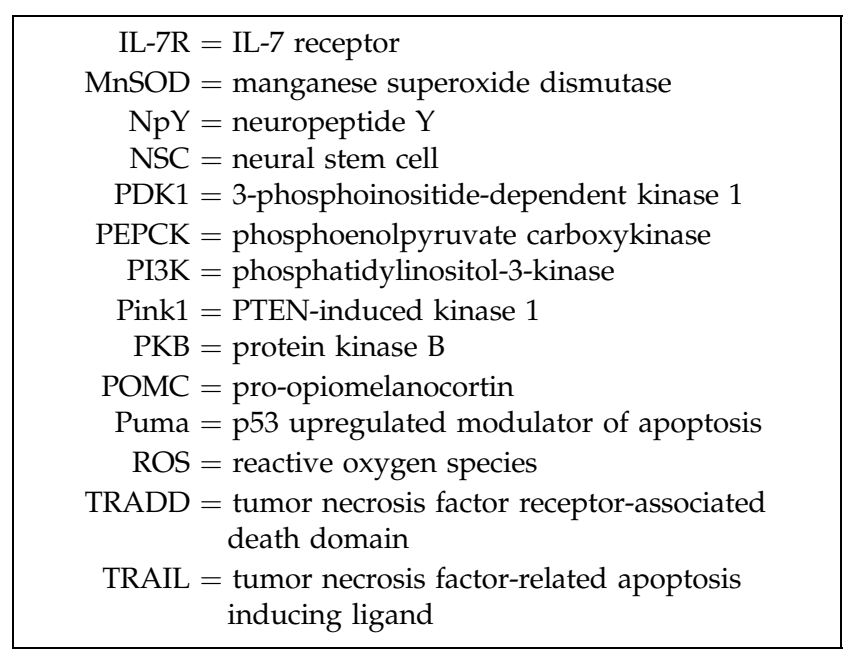

